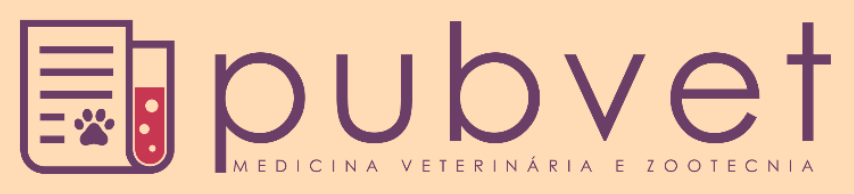

https://doi.org/10.31533/pubvet.v14n5a567.1-6

\title{
Micção inapropriada em um gato doméstico: tratamento bem sucedido com fluoxetina
}

\author{
Priscila Alves de Lima Moraes Bastos ${ }^{1 * \bullet}$, Mariana Palha de Brito Jardim ${ }^{2} \bullet$, Luiza Freire de \\ Farias $^{30}$, Carolina Haje Ramos ${ }^{4}$, Heloisa Justen Moreira de $\operatorname{Souza}^{50}$, Thereza Cristina de \\ Vasconcelos $^{6}$
}

${ }^{I}$ Graduanda em medicina veterinária, Universidade do Grande Rio, Rio de janeiro, RJ Brasil.

${ }^{2}$ Doutoranda pelo Programa de Pós Graduação em Medicina Veterinária, Universidade Federal Rural do Rio de Janeiro, Departamento de Medicina e Cirurgia Veterinária, Rio de Janeiro, RJ Brasil.

${ }^{3}$ Mestre pelo programa de Pós Graduação em Medicina Veterinária, Universidade Federal Rural do Rio de Janeiro, Departamento de Medicina e Cirurgia Veterinária, Rio de Janeiro, RJ Brasil.

${ }^{4}$ Graduada pela Universidade Castelo Branco, Rio de Janeiro, RJ Brasil.

${ }^{5}$ Professora associada da Universidade Federal Rural do Rio de Janeiro, RJ Brasil.

${ }^{6}$ Docente do curso de medicina veterinária, Universidade do Grande Rio, Rio de Janeiro, RJ Brasil.

*Autor para correspondência, E-mail: pri.almb@gmail.com

\begin{abstract}
Resumo. Micção inapropriada na medicina felina compreende o comportamento dos gatos domésticos de urinar por qualquer motivo em locais indesejáveis para os tutores. Felinos com alterações comportamentais apresentam duas a seis vezes mais chance de serem abandonados. Um gato sem raça definida, macho, esterilizado aos seis meses de vida, com idade correspondente a quatro anos, foi levado para atendimento. A queixa do tutor se concentrava em eliminação de urina em locais indesejáveis, tais como roupas, sofá e cama dos cães, através do histórico e anamnese verificou-se que o felino no ato da consulta tinha hábito de vida estritamente domiciliado e que tal comportamento de micção inadvertida havia se iniciado após mudança do tutor, o qual residia anteriormente em uma moradia mais ampla, onde os gatos tinham hábitos peridomiciliados. O exame clínico, exames laboratoriais (hemograma e bioquímicas séricas), glicemia, teste para detecção de antígeno correspondente ao vírus da leucemia felina (FeLV) e anticorpo contra o vírus da imunodeficiência felina (FIV) e a ultrassonografia abdominal do felino não resultaram em alterações dignas de nota. Desta forma, mediante o diagnóstico de eliminação relacionada a fatores ambientais/sociais primários, adotou-se medidas de enriquecimento ambiental que não resultaram em resposta satisfatória, instituindo-se terapia farmacológica com cloridrato de fluoxetina na dose de $0,5 \mathrm{mg} / \mathrm{kg}$ por via oral, a cada 24 horas, até novas recomendações. $\mathrm{O}$ animal apresentou melhora do quadro de eliminação inapropriada 10 dias após a instituição do tratamento medicamentoso e 12 meses após permanece sem sinais de periúria. Não foi observado efeito colateral associado a terapia adotada. Os fatores que desencadeiam o transtorno de eliminação inaceitável não necessariamente são os que os mantêm, desta forma justifica-se a não resposta somente ao manejo ambiental adotado. e muitos animais acabam sendo submetidos a eutanásia. Objetivou-se com este trabalho relatar um caso de micção inapropriada em felino doméstico onde houve resposta satisfatória ao tratamento farmacológico com cloridrato de fluoxetina. Tal relato pode contribuir para melhor compreensão e adoção de técnicas de tratamento para o transtorno da micção inapropriada em gatos, o que pode auxiliar na redução da insatisfação do tutor com felinos que manifestam tal comportamento e consequentemente diminuir o número de animais abandonados e eutanasiados por apresentarem tal transtorno.
\end{abstract}

Palavras chave: felinos, inaceitável, micção, urina 


\title{
Inappropriate urination in a domestic cat: Successful fluoxetine treatment
}

\begin{abstract}
Inappropriate urination in feline medicine embraces the behavior of domestic cats to urinate for no specific reason in undesirable places for their guardians. Cats with behavioral problems are two to six times more likely to be abandoned and many animals are euthanized. The aim of this paper is to report a case of inappropriate urination in a domestic cat, from which a satisfactory response was observed in pharmacological treatment with fluoxetine hydrochlorid. A male domestic breed, male, sterilized at six months of age, four years old, was taken for clinical care. The tutor's complaint focused on the elimination of urine in undesirable places, such as dog's bed, sofa. Through history and anamnesis, it was found that the feline at the time of the consultation had a strictly domiciled habit of living and that such behavior of Inappropriate urination had started after moving to a new apartment. The owner used to live in a larger home where cats had peridomiciliated habits. Clinical examination, laboratory tests (blood count and serum biochemistry), blood glucose, feline leukemia virus (FeLV) antigen and feline immunodeficiency virus (FIV) antibody testing and feline abdominal ultrasound did not result in changes. Noteworthy. Thus, through the diagnosis of elimination related to primary environmental / social factors, environmental enrichment measures were adopted that did not result in a satisfactory response. Consequently, the pharmacological therapy was prescribed with fluoxetine hydrochloride at a dose of $0.5 \mathrm{mg} / \mathrm{kg}$ orally every 24 hours until further recommendations. The animal presented improvement during the first 10 days after the start of drug treatment and 12 months after it remained without signs of periuria. There was no side effect associated with the therapy adopted. The factors that trigger the inappropriate elimination disorder are not necessarily those that maintain them, therefore justifying the non-response only to the environmental management adopted. Such a report may contribute to a better understanding and adoption of treatment techniques for inadvertent urination disorder in cats, which may help to reduce the tutor's dissatisfaction with felines that exhibit such behavior and consequently reduce the number of animals abandoned and euthanized because of this disorder.
\end{abstract}

Keywords: feline, unacceptable, urination, urine

\section{Micción inapropiada en un gato doméstico: tratamiento exitoso con fluoxetina}

Resumen. La micción inapropiada en la medicina felina comprende el comportamiento de los gatos domésticos para orinar por cualquier motivo en lugares indeseables para los guardianes. Los gatos con cambios de comportamiento tienen de dos a seis veces más probabilidades de ser abandonados y muchos animales son sacrificados. El objetivo de este estudio fue informar un caso de micción inapropiada en un gato doméstico donde hubo una respuesta satisfactoria al tratamiento farmacológico con clorhidrato de fluoxetina. Un felino doméstico, esterilizado a los seis meses de edad, de cuatro años de edad, fue atendido. La queja del tutor se centró en la eliminación de orina en lugares indeseables, como ropa, sofá y cama dos perros, a través de la historia y la anamnesis, se encontró que el felino en el momento de la consulta tenía un hábito de vida estrictamente domiciliado y que tal comportamiento de la micción involuntaria había comenzado después del cambio de tutor, que anteriormente residía en un hogar más grande donde los gatos tenían hábitos peridomiciliados. El examen clínico, las pruebas de laboratorio (hemograma y bioquímica sérica), la glucosa en sangre, el antígeno del virus de la leucemia felina (FeLV) y las pruebas de anticuerpos del virus de la inmunodeficiencia felina (FIV) y la ecografía abdominal felina no produjeron resultados dignos de mención, Por lo tanto, a través del diagnóstico de eliminación relacionado con factores ambientales / sociales primarios, se adoptaron medidas de enriquecimiento ambiental que no dieron como resultado una respuesta satisfactoria, y se instituyó la terapia farmacológica con clorhidrato de fluoxetina 
a una dosis de $0.5 \mathrm{mg} / \mathrm{kg}$ por vía oral. cada 24 horas hasta nuevas recomendaciones. El animal mejoró incorrectamente, se eliminó 10 días después del inicio del tratamiento farmacológico y 12 meses después de que permaneció sin signos de periuria. No hubo efectos secundarios asociados con la terapia adoptada. Los factores que desencadenan el trastorno de eliminación inaceptable no son necesariamente los que los mantienen, lo que justifica la no respuesta solo a la gestión ambiental adoptada. Este informe puede contribuir a una mejor comprensión y adopción de técnicas de tratamiento para el trastorno de micción inapropiado en gatos, lo que puede ayudar a reducir la insatisfacción del tutor con los felinos que manifiestan tal comportamiento y, en consecuencia, reducir el número de animales abandonados y sacrificados por presentar tal desorden.

Palabras clave: felino, inaceptable, micción, orina

\section{Introdução}

Micção inapropriada na medicina felina compreende o comportamento dos gatos domésticos de urinar por qualquer motivo em locais indesejáveis para os tutores, ou seja, geralmente fora de suas liteiras (Borns-Weil, 2018) sendo um dos distúrbios comportamentais mais comuns em felinos domésticos (Dantas, 2018). Os felinos afetados por esse transtorno podem deixar de usar a liteira e a micção geralmente ocorre em superfícies horizontais (Ramos et al., 2019).

Patologias como doenças do trato urinário inferior, doença renal, diabetes mellitus, hipertireoidismo, cistite idiopática felina, osteoartrose, disfunção cognitiva e neoplasias podem cursar com periúria em gatos (Barcelos et al., 2018; Carney et al., 2014). Desta forma, há necessidade de se realizar um exame clínico minucioso, além de avaliações laboratoriais, a fim de se excluir enfermidades que culminam com micção indevida.

As alterações de comportamento são as principais causas de abandono de felinos, gatos que apresentam esse tipo de distúrbio tem duas a seis vezes mais chance de serem abandonados, além de alguns tutores optarem pela eutanásia. Há ainda o enfraquecimento do vínculo entre o tutor e o felino e como consequência menor cuidado veterinário, o que impacta diretamente na saúde do animal (BornsWeil, 2018; Onodera et al., 2014; Paz et al., 2017).

Objetivou-se com este trabalho relatar um caso de micção inapropriada em um felino doméstico onde houve resposta satisfatória ao tratamento farmacológico com fluoxetina.

\section{Relato de caso clínico}

Um felino doméstico, sem raça definida, macho, esterilizado aos seis meses de vida, com idade correspondente a quatro anos e peso igual a $5,470 \mathrm{~kg}$ foi levado para atendimento em uma clínica particular exclusiva para atendimento de gatos domésticos. A queixa do tutor tangia o fato do felino urinar em locais inapropriados como na cama dos dois cães que coabitavam a residência, gaveta de roupas do tutor e no sofá, ou seja, em superfícies horizontais.

Durante a anamnese e histórico do paciente, que no ato da consulta possuía o hábito de vida estritamente domiciliado, foi verificado que tal comportamento teve início após mudança de domicílio por parte do tutor, o qual residia em um apartamento de maior metragem anteriormente, onde os gatos eram peridomicialidos. Foi verificado que o animal apresentava comportamento característico pré e pós eliminação nos locais indesejados, bem como agachar, cavar, rodear, eliminar grande quantidade de urina e após tentar cobrir o dejeto eliminado. Havia mais dois cães esterilizados e um gato também esterilizado, que conviviam harmonicamente com o felino em questão. $\mathrm{O}$ tutor informou possuir uma caixa sanitária e dispender 5\% do seu tempo diário em interação com os animais da casa.

Em relação aos exames prévios dignos de nota, foi verificado que o felino já havia sido testado anteriormente para detecção do antígeno correspondente ao vírus da leucemia felina (FeLV) e anticorpo contra o vírus da imunodeficiência felina (FIV) através do método sorológico ELISA, o qual resultou em negativo para ambas as doenças. No exame clínico o paciente encontrava-se com temperamento receptivo, escore de condição corporal 5/9, mucosas normocoradas, normohidratado, sem patologias detectáveis em cavidade oral, com frequência cardíaca igual a 140 batimentos por minuto, frequência 
respiratória correspondente a 35 movimentos por minuto, sem alteração quanto a ausculta pulmonar, bem como a palpação abdominal e renal, a temperatura retal no ato do exame foi igual a $38,6^{\circ} \mathrm{C}$, o felino deambulou no consultório e não foi notado alteração de marcha.

Após exame do animal, realizou-se coleta de amostra sanguínea por venopunção cefálica para avaliação do hemograma e seguintes bioquímicas séricas: ureia, creatinina, alanina aminotransferase (ALT), proteínas totais e frações e potássio, além de repetição do teste de FIV e FeLV por método sorológico. Realizou-se ainda coleta de urina por cistocentese para exames de urinálise, cultura e antibiograma de aeróbios. Ademais foi solicitado ao tutor a realização do exame de ultrassonografia abdominal. Não foram verificados indícios de quaisquer alterações patológicas nos exames laboratoriais e imagiológico solicitados.

A glicemia foi aferida com glicosímetro no consultório e se encontrava $105 \mathrm{mg} / \mathrm{dl}$, intervalo de referência 90 a $120 \mathrm{mg} / \mathrm{dl}$.

Desta forma, mediante a exclusão de causas de doença metabólica e diagnóstico de eliminação relacionada a fatores ambientais/sociais primários, foi indicado ao tutor adotar medidas de enriquecimento ambiental, tais como brincadeiras diárias, pelo menos três vezes ao dia com duração de 10 minutos com objetos que mimetizavam o hábito de caça, introdução de áreas de verticalização, a exemplo de prateleiras, bem como arranhadores e novas liteiras de variados tamanhos e com diferentes substratos, a serem dispostas na residência de forma distante uma das outras, ofertando ao felino maior possibilidade de urinar em locais desejáveis.

Após 30 dias das novas medidas, o felino retornou para revisão clínica não havendo relato de melhora do quadro de micção inadvertida, assim foi associado ao manejo ambiental o tratamento farmacológico com cloridrato de fluoxetina (farmácia de manipulação Barraderm), a ser administrado na dose de 0,5 $\mathrm{mg} / \mathrm{kg}$ por via oral, a cada 24 horas até novas recomendações.

Após 10 dias, o animal apresentou melhora do quadro relatado, passando a urinar exclusivamente nas liteiras, permanecendo estável quanto ao transtorno após 12 meses da introdução da terapia medicamentosa. Não houve relato de nenhum efeito colateral associado a medicação.

\section{Discussão}

Certos distúrbios metabólicos podem contribuir para o transtorno de micção inapropriada sendo de suma importância o exame clínico detalhado, exames laboratoriais, tais como: hemograma, urinálise, urocultura e antibiograma, bioquímicas séricas, tiroxina (T4 total - em animais com idade superior a oito anos) e ultrassonografia abdominal devem ser realizados com o intuito de descartar comorbidades (Borns-Weil, 2018; Curtis, 2015). Assim através da triagem clínica adotada para o felino do atual estudo não foi encontrada nenhuma doença metabólica que pudesse justificar a micção inapropriada. Contudo, apesar da exclusão de causas médicas, não foi possível descartar a possibilidade do animal ser portador de cistite idiopática felina, visto a não existência de teste diagnóstico especifico ou confirmatório para tal condição (Carney et al., 2014).

O comportamento de micção inadvertida difere do transtorno de marcação territorial, onde no último caso o felino continua usando a caixa de areia normalmente, entretanto em certos locais a urina é eliminada em pequenos jatos verticais (Horwitz, 2019; Ramos et al., 2018). Tal comportamento se deve ao fato de a marcação estar relacionada a áreas centrais para o gato, o qual costuma marcar locais com significado social como janelas, portas, itens novos, corredores e pés de móveis.

A orquiectomia costuma ser suficiente para reduzir esse transtorno comportamental (Calixto \& Justen, 2007). Gatos castrados antes da puberdade tem menor risco de apresentar o distúrbio de marcação (Paz et al., 2017; Vogt et al., 2010). Com isso, presume-se que o felino em questão não apresentava comportamento de marcação territorial, já que o mesmo urinava em superfícies horizontais, as quais não correspondiam as áreas centrais da casa, além de ter sido esterilizado quando jovem.

Outro fato que diferencia esse caso de micção territorial, seria o fato do paciente apresentar comportamento normal pré e pós eliminação, como postura agachada no momento da micção, assim como grande quantidade de urina depositada e tentativa de cobrir a excreta, o que não é visto na marcação, onde o animal apresenta postura em pé, urina pouco e tem ausência de comportamento de cobertura (Heath, 2019). Fatores de estresse podem desencadear a periúria, tais como modificações na 
rotina da casa e mudanças de residência (Amat et al., 2016; Borns-Weil, 2018; Tomlinson, 2016). A alteração comportamental do gato em questão foi notada após a mudança de domicílio, possivelmente sendo o fator desencadeador do transtorno, assim sustenta-se o diagnóstico de eliminação relacionada a fatores ambientais ou sociais primários.

A convivência hostil interespécies na moradia, além da introdução de novos animais ou pessoas, o número excessivo de felinos e/ou ausência do dono, também podem ser fatores de estresse e fomentarem o distúrbio de micção inadvertida (Halls \& Heath, 2015). Essa questão não está relacionada ao caso, visto que os animais apresentavam convivência harmônica e o tutor interagia com os animais de forma frequente. De acordo com Paz et al. (2017) animais que vivem em lares com até três gatos tem três vezes mais chance de apresentarem micção inapropriada. Isso provavelmente se deve ao fato de a quantidade de vasilhas sanitárias ser insuficiente, sendo o ideal uma liteira para cada gato da casa, mais uma. Exemplo, um tutor com dois gatos deveria ter três caixas sanitárias. Assim pode-se perceber que o número de liteiras que o tutor possuía era inicialmente insuficiente.

Segundo Barcelos et al. (2018) liteiras e substratos que não agradam os gatos podem ser a causa de alterações de comportamento. Assim, a introdução de novas caixas de areia, com diferentes tamanhos, substratos e dispostas em diferentes localizações da casa, além de brincadeiras que redirecionem o gato a outro comportamento constituem o manejo ambiental a se adotar na tentativa de resolução do transtorno (Carney et al., 2014). Todavia, no atual trabalho a micção inapropriada persistiu mesmo após o enriquecimento ambiental ter sido instituído.

Os fatores que desencadeiam o transtorno de eliminação inapropriada não necessariamente são os que os mantém (Borns-Weil, 2018). Assim, no caso relatado a micção inadvertida pode ter se iniciado pela mudança do ambiente, o que gerou estresse ao animal e fez com que ele iniciasse a eliminação de urina em locais indesejáveis, contudo ao se deparar com superfícies de maior absorção dos dejetos, o comportamento inadequado pode ter sido mantido por tal preferência, visto que felinos com periúria costumam urinar em locais onde a absorção é rápida como, por exemplo, em roupas (Dantas, 2017). Desta forma justifica-se a não resposta somente ao manejo ambiental adotado. Previamente ao início da terapia farmacológica é recomendado iniciar o enriquecimento ambiental, visto que a medicação não substitui o manejo do ambiente (Carney et al., 2014).

De acordo com Carney et al. (2014) uma das indicações terapêuticas recomendadas para o tratamento da eliminação inapropriada é a utilização do cloridrato de fluoxetina, o qual tem como mecanismo de ação a forte inibição da receptação da serotonina. A dose sugerida é de 0,5 a $1,3 \mathrm{mg} / \mathrm{kg}$, a ser administrada por via oral, cada 24 horas, devendo se utilizar a menor dose efetiva. Os efeitos colaterais potenciais incluem inapetência, vômitos, letargia (raro) e retenção de urina, o que não foi observado no presente estudo.

\section{Conclusão}

Pelo presente relato foi possível avaliar combinadas técnicas de tratamento para micção inapropriada em um felino doméstico, o qual apresentava o distúrbio de eliminação relacionado a fatores ambientais/sociais primários, havendo resposta positiva ao tratamento com o cloridrato de fluoxetina, não ocorrendo efeitos colaterais com o uso da medicação. Tal relato pode contribuir para melhor compreensão e adoção de técnicas de tratamento para o transtorno de miç̧ão inadvertida em gatos, o que pode auxiliar na redução da insatisfação do tutor com os felinos que apresentam tal comportamento e consequentemente diminuir o número de animais abandonados e eutanasiados por apresentarem tal transtorno.

\section{Referências bibliográficas}

Amat, M., Camps, T., \& Manteca, X. (2016). Stress in owned cats: behavioural changes and welfare implications. Journal of Feline Medicine and Surgery, 18(8), 577-586.

Barcelos, A. M., McPeake, K., Affenzeller, N., \& Mills, D. S. (2018). Common risk factors for urinary house soiling (periuria) in cats and its differentiation: the sensitivity and specificity of common diagnostic signs. Frontiers in Veterinary Science, 5, 1-12. https://doi.org/https://doi.org/10.3389/fvets.2018.00108. 
Borns-Weil, S. (2018). Inappropriate Urination. Small Animal Practice, 1, 1-15.

Calixto, R., \& Justen, H. (2007). Avaliação do efeito da castração e de variáveis ambientais sobre a marcação por urina e fezes em gatos (Felis catus). Acta Scientiae Veterinariae, 35(2), 145-152.

Carney, H. C., Sadek, T. P., Curtis, T. M., Halls, V., Heath, S., Hutchison, P., Mundschenk, K., \& Westropp, J. L. (2014). AAFP and ISFM guidelines for diagnosing and solving house-soiling behavior in cats. Journal of Feline Medicine and Surgery, 16(7), 579-598.

Curtis, T. M. (2015). Feline inappropriate urination. Today's Veterinary Practice, 1, 45-48.

Dantas, L. M. S. (2018). Vertical or horizontal? Diagnosing and treating cats who urinate outside the box. Veterinary Clinics: Small Animal Practice, 48(3), 403-417.

Halls, V., \& Heath, S. (2015). Treatment in cases of feline house soiling. The Veterinary Nurse, 6(8), 462-467. https://doi.org/https://doi.org/10.12968/vetn.2015.6.8.462.

Heath, S. (2019). Common feline problem behaviours: unacceptable indoor elimination. Journal of Feline Medicine and Surgery, 21(3), 199-208. https://doi.org/ 10.1177\%2F1098612X19831202.

Horwitz, D. F. (2019). Common feline problem behaviors: Urine spraying. Journal of Feline Medicine and Surgery, 21(3), 209-219. https://doi.org/https://doi.org/10.1177\%2F1098612X19831203.

Onodera, N., Uchida, K., \& Kakuma, Y. (2014). Association between characteristics of cats and satisfaction of owners who adopted cats from an animal hospital in Japan. Journal of Veterinary Medical Science, 76(5), 729-733. https://doi.org/https://doi.org/10.1292/jvms.12-0569.

Paz, J. E. G., Machado, G., \& Costa, F. V. (2017). Factors associated with behavior problems in cats. Pesquisa Veterinária Brasileira, 37(11), 1336-1340.

Ramos, D., Reche-Junior, A., Mills, D. S., Fragoso, P. L., Daniel, A. G. T., Freitas, M. F., Cortopassi, S. G., \& Patricio, G. (2019). A closer look at the health of cats showing urinary house-soiling (periuria): a case-control study. Journal of Feline Mdicine and Surgery, 21(8), 772-779. https://doi.org/https://doi.org/10.1177\%2F1098612X18801034.

Tomlinson, C. (2016). Toileting troubles part 1: factors influencing house soiling in cats and dogs. Companion Animal, 21(6), 351-357. https://doi.org/https://doi.org/10.12968/coan.2016.21.6.351.

Vogt, A. H., Rodan, I., Brown, M., Brown, S., Buffington, C. A. T., Forman, M. J. L., Neilson, J., \& Sparkes, A. (2010). AAFP-AAHA: feline life stage guidelines. Jornal of Feline Medicine and Surgery, 12, 43-54.

Recebido: 25 de novembro, 2019.

Aprovado: 3 de janeiro, 2020.

Disponível online: 16 de junho, 2020.

Licenciamento: Este artigo é publicado na modalidade Acesso Aberto sob a licença Creative Commons Atribuição 4.0 (CC-BY 4.0), a qual permite uso irrestrito, distribuição, reprodução em qualquer meio, desde que o autor e a fonte sejam devidamente creditados. 